\title{
Maternal and Fetal Outcome in Gestational Diabetes Mellitus
}

\author{
Akhter $\mathrm{S}^{1}$, Karim MR ${ }^{2}$ \\ DOI:https://doi.org/10.3329/jafmc.v16i2.55291
}

\begin{abstract}
Introduction: Gestational diabetes mellitus (GDM) is a problem of growing interests both for the mother \& the baby. Like other South East Asia countries the prevalence of GDM has also been progressively increasing in Bangladesh. Some population based studies conducted in Bangladesh have revealed an increasing trend of GDM prevalence ranging from $6 \%$ to $14 \%$ based in using different diagnostic criteria.
\end{abstract}

Aim: To assess the fetal and maternal outcome in pregnancies complicated by gestational diabetes mellitus.

Materials and Methods: This cross sectional study was conducted in Combined Military Hospital Dhaka from April 2018 to April 2019. Total 100 cases of GDM admitted in antenatal ward were taken into considerations. Maternal \& fetal outcome was studied.

Results: Study revealed that gestational diabetes was more common among $>25$ years old multiparous women. 88\% GDM diagnosed at more than 20 weeks of gestation and more than $76 \%$ mothers with gestational diabetes delivered by caesarean section, 23\% delivered vaginally. Pre-eclampsia were noted in $18 \%$ of patients. $25 \%$ babies were macrosomic at birth. $12 \%$ babies had hyperbillirubanaemia, $10 \%$ respiratory distress, $1 \%$ had congenital anomalies.

Conclusion: Gestational diabetes mellitus is common with a rising prevalence and is associated with higher maternal and neonatal morbidity. It carries additional long term health consequences for the mother and her offspring. Diagnosis and appropriate treatment of the condition decreases morbidities for the mother \& baby.

Key-words: Gestational diabetes, Fetal outcome, Maternal outcome.

\section{Introduction}

Gestational diabetes mellitus is defined as any degree of glucose intolerance with onset or first recognized during pregnancy with or without remission after the end of pregnancy $y^{1,2,3}$. GDM is not only associated with fetal and neonatal morbidity and mortality but also abnormal growth \& development (40\%), cognitive impairment (24\%), and chronic disease in later life ${ }^{4}$.

Pregnancy causes changes in maternal carbohydrate metabolism. With increase in gestational age insulin resistance and diabetogenic stress due to placental hormone causes increase in insulin secretion as a compensatory mechanism. When this balance is inadequate, gestational diabetes occurs. In 2015, International diabetic federation (IDF) estimated that 20.9 million (16.2\%) live births were affected by hyperglycaemia in pregnancy and an estimated $85.1 \%$ of those cases were due to gestational diabetes ${ }^{5}$. The optimal screening regimen for GDM remains controversial. There is utmost need for action to standardize GDM screening and diagnostic criteria. Should testing for GDM be a one-step (the $75 \mathrm{~g}$ oral glucose tolerance test OGTT) or two -step (the 50 glucose challenge test, GCT followed by $75 \mathrm{~g}$ OGTT) procedure ${ }^{6}$.

Higher prevalence of GDM was observed in the higher age group, higher gravidity, higher BMI, and those with hypertension and family history of diabetes. The history of abortions, neonatal death, and still birth were found higher among the GDM mothers than non GDM mothers ${ }^{7}$. Hospital based studies have found that antepartum and intrapartum complications are more common among pregnant diabetic women. Ninety percent women delivered by caesarian section because of Post CS, repeat CS, breech presentation, preeclampsia, fetal distress, and obstructed labour. Maternal mortality was $1.44 \%$, and fetal perinatal mortality was $8.6 \%{ }^{8}$.

\section{Materials and Methods}

This study was carried out combined military hospital Dhaka. The data collection was performed over a period from April 2018 to April 2019. It was a cross sectional study which included both outdoor (OPD) and admitted patients. Informed consent was taken from all the patients (the records consisted of personal identification such as age, parity). All antenatally registered patients were screened for high risk factors for gestational diabetes like previous abortion, intrauterine death, previous history of big baby, history of GDM previous pregnancy, history of congenital anomalous baby, history of polyhydromnios.

Testing venous blood of all antenatal women for fasting blood glucose (FBS) and 2 hours after breakfast at 24-28 weeks gestation was the routine practice followed. If the FBS $>92 \mathrm{mg} / \mathrm{dl}$ and PLBS was $>140 \mathrm{mg} / \mathrm{dl}$ these values were considered abnormal for the pregnancy and the patient was evaluated further by oral glucose tolerance test (OGTT) to confirm diagnosis of GDM.

Women who had documented evidence of diabetes mellitus prior to pregnancy irrespective whether on treatment or not were excluded from the study. Detailed examination done. Various parameter were noted like mode of delivery, fetal weight, maternal and neonatal complications and neonatal intensive care admission. Statistical analysis was done using SPSS $v 20$.

1. Lt Col Shahnaz Akhter, MBBS, DGO, FCPS, Associate Professor of Gynaecology \& Obstetrics, Armed Forces Medical College, Dhaka (E-mail: Shahnazm250 @gmail.com) 2. Dr Md. Rizwanul Karim, MBBS, MPH, Associate Professor of Community Medicine, Rajshahi Medical College, Rajsashi. 


\section{Results}

Out of 100 patients nearly $55 \%(n=55)$ patients were in age group $26-30$ years, $30 \%$ were above age 30 years. Majority i.e. $88 \%$ was diagnosed after 20 weeks of gestation while $12 \%$ were diagnosed before 20 weeks. Among all patient $16 \%$ had family history of diabetes mellitus in first degree relatives (Table-I). Among them $72 \%(n=72)$ were multigravida (Figure-1). Among the respondents $88 \%$ patient fall in 6-10 kg weight gain category. Minimum weight gain was $5 \mathrm{~kg}$ and maximum weight gain was $10 \mathrm{~kg}$.

Table-l: Age and gestational age categories of the respondents $(n=100)$

\begin{tabular}{|c|c|c|}
\hline $\begin{array}{c}\text { Age of the } \\
\text { respondents }\end{array}$ & Number & $\%$ \\
\hline $21-25$ & 15 & 15 \\
\hline $26-30$ & 55 & 55 \\
\hline$>30$ & 30 & 30 \\
\hline Gestational age category & No $(\mathrm{n})$ & $\%$ \\
\hline$<20$ weeks & 12 & 12 \\
\hline =>20 weeks & 88 & 88 \\
\hline
\end{tabular}

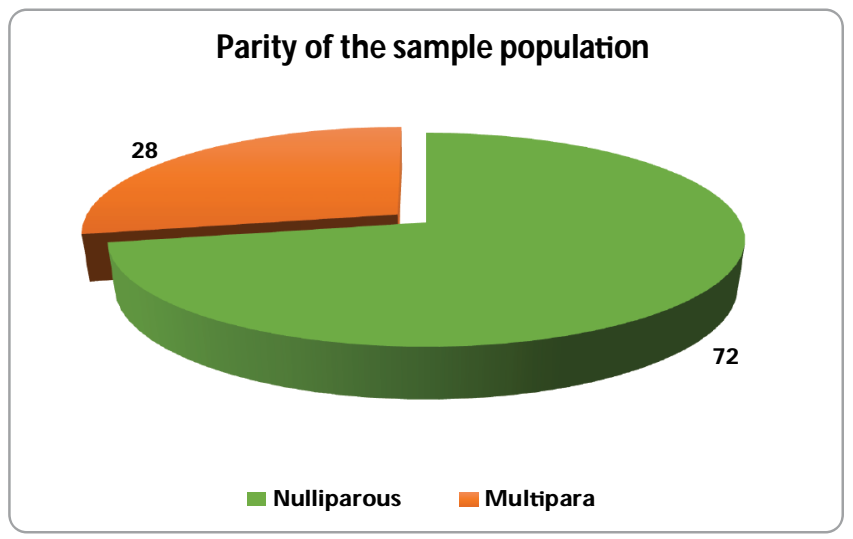

Figure-1: Parity of the respondents $(n=100)$

During ANC risk factors were detected in 60\% patients. Preeclampsia complicating pregnancy was noted in 18 patients (18\%), hypothyroidism was seen in 3 patients (3\%), polyhydromnios $4 \%$ and preterm labour seen in 12\% patients. Intra uterine growth retardation (IUGR) was noted in 3\% patients, other high risk factors include previous lower segment cesarean section (LSCS), breech presentation, transverse lie and placenta previa (20\%) (Table-II).

Table-II: Associated maternal complications ( $n=100)$

\begin{tabular}{|c|c|c|}
\hline Type of complication & No $(\mathbf{n})$ & $\%$ \\
\hline Pre-eclampsia & 18 & 18 \\
\hline Polyhydramnios & 4 & 4 \\
\hline Preterm labour & 12 & 12 \\
\hline IUGR & 3 & 3 \\
\hline Bad obstetric history & 3 & 3 \\
\hline Others & 20 & 20 \\
\hline No symptoms & 40 & 40 \\
\hline Total & 100 & 100 \\
\hline
\end{tabular}

Most of the babies delivered ( $n=48$ ) were full term, but $40 \%$ were preterm and $8 \%$ extreme preterm . Almost three fourth (76\%) of the patients delivered by caesarian section and $23 \%$ patients delivered vaginally, (Figure-2).

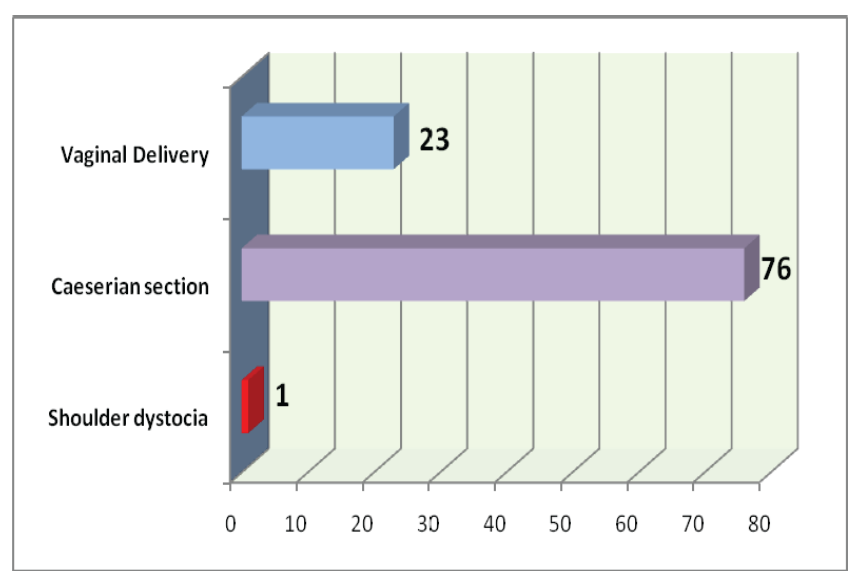

Figure-2: Type of delivery among respondents $(n=100)$

Only $1 \%$ patient was detected with shoulder dystocia. Postpertum hemorrhage occurred in $2(2 \%)$ patients. Three patients of LSCS had wound infection. In the study three categories of treatment were observed. Only diet restriction (25\%), only insulin therapy (45\%) and both diet and insulin therapy(30\%). (Table-III).

Table-III: Distribution of patients according to received treatment $(n=100)$

\begin{tabular}{|l|c|c|}
\hline \multicolumn{3}{|c|}{ Treatment received by GDM mothers } \\
\hline Treatment category & Number & $\%$ \\
\hline Only diet restriction & 25 & 25 \\
\hline Only insulin therapy & 45 & 45 \\
\hline Both diet and insulin therapy & 30 & 30 \\
\hline
\end{tabular}

Almost three fourth that is $68 \%$ (68) babies were $2.5-3.5 \mathrm{~kg}, 25 \%$ babies were $>3.5 \mathrm{~kg}$, only 7 babies $(7 \%)$ were less than $<2.5 \mathrm{~kg}$ (Figure-3).

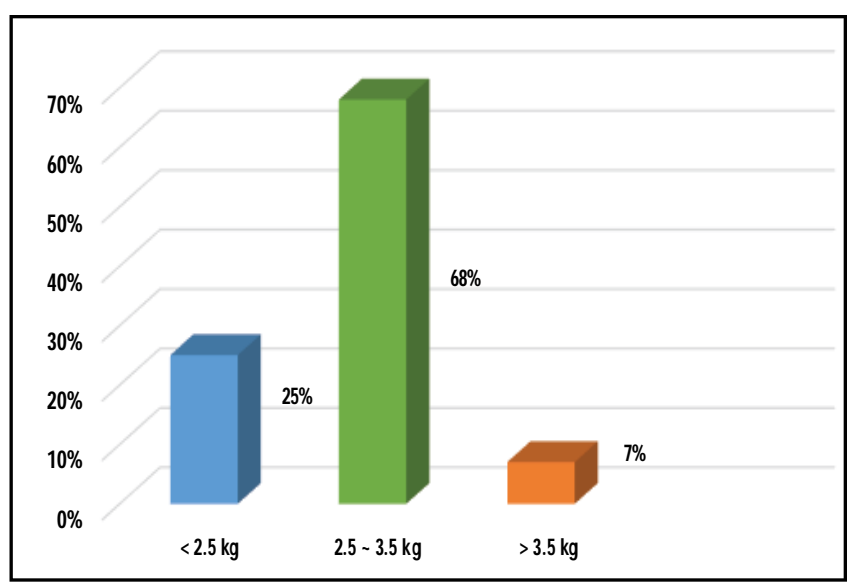

Figure-3: Birth weight of babies delivered by GDM mothers $(n=100)$ 
Out of 100 newborn $62 \% \quad(n=62)$ had normal outcome and $38 \%$ had neonatal complications. $26.4 \%$ developed respiratory distress, $31.5 \%$ developed neonatal jaundice, and $2.6 \%$ had congenital cardiac disease (Ventricular septal defect). 21\% (8) babies had hypoglycemia, 10.5\% had meconium aspiration syndrome (MAS) and $8 \%$ neonatal sepsis. No still birth occurred (Table-IV).

Table-IV: Distribution of patients according to neonatal complications $(\mathrm{n}=38)$

\begin{tabular}{|l|c|c|}
\hline Neonatal complications & Number & $\%$ \\
\hline Hyperbillirubinaemia & 12 & 31.5 \\
\hline Respiratory distress & 10 & 26.4 \\
\hline Hypoglycaemia & 8 & 21 \\
\hline Neonatal sepsis & 3 & 8 \\
\hline MAS & 4 & 10.5 \\
\hline Congenital anomalies & 1 & 2.6 \\
\hline
\end{tabular}

\section{Dscussion}

The present study was undertaken in a teaching hospital to identify cases of gestational diabetes mellitus, to study their obstetric and fetal outcome. According to this study about $30 \%$ cases of GDM above 30 years of age and $55 \%$ above the age of 25 years. In a study done at a tertiary care hospital (BIRDEM), it was observed that GDM affects mostly the mothers aged $>25 y$ ears age. ${ }^{9}$ In another study by Farooq MU et al 44(88\%) patients were above 25 years of age ${ }^{10}$.

In present study, the incidence of gestational diabetes increased with parity such as in primi it was $28 \%$ and multipara $72 \%$. Similar observations were made by Sajani TT et al 67\% GDM mothers were multipara where $33 \%$ were primi ${ }^{9}$. Another study by Kumari SS et al cited that the prevalence of GDM was higher in multigravida with $63 \%$ where the primi were $16.90 \%{ }^{11}$. one of the possible explanations for this is gravity increases with increase of age. The stress on Beta cells of pancreas increases so does the insulin resistance, hence the incidence of GDM rises with parity.

This study showed that patients with GDM had complications like preeclampsia (18\%), polyhydromnios 4\%), preterm labour (12\%), IUGR (3\%), Hypothyroidism (4\%). Dahiya K et al reported that women with GDM have higher proportion of obstetric complications including polyhydromnios (11.2 times), pre-eclampsia (1.91 times), IUGR (3.9 times) , intrauterine death (1.4 times), preterm labour (1.6times), preeclampsia (1.9times) and congenital malformation of fetus (1.9 times) $)^{12}$. In this study it was observed that $16 \%$ had family history of diabetes mellitus. It was found higher (74.3\%) in other study?

In this study, $76 \%$ of patients having GDM delivered by caesarean section and $23 \%$ delivered by normal delivery. Many studies have found high caesarian delivery rates in GDM patients despite good maternal blood glucose control during pregnancy ${ }^{13,14}$. Faroog MU et al found caesarian section was done in $58 \%$ patients $^{10}$. Joy et al found $83.8 \%$ of women underwent caesarean delivery, only $16.2 \%$ had normal delivery ${ }^{15}$. According to Yajnik et al, the incidence of caesarian section in patients with GDM was found to be $60 \%{ }^{16}$. In this study, most of the GDM mothers were treated with insulin therapy; Only insulin therapy 45\%, 30\% received both diet restriction and insulin therapy. This treatment modalities were quite similar to other studies ${ }^{10,17}$.

Most common neonatal complications in present study was neonatal hyperbillirubinaemia (12\%), then respiratory distress $(10 \%)$ and hypoglycaemia (8\%), meconium aspiration syndrome $4 \%$, neonatal sepsis $3 \%$. Dahiya $\mathrm{K}$ et al cited in their study fetal outcome was significantly poor in the GDM mothers. The incidence of macrosomia was higher in GDM group. Hypoglycaemia was seen in $5.7 \%$, hyperbillirubinaemia in $11.4 \%$, respiratory distress syndrome in $5.7 \%$ babies $^{18}$. In another study Sajani TT et al found $32.1 \%$ was neonatal hyperbillirubinaemia, $1.8 \%$ had congenital anomaly or birth defect, Macrosomia was $1.8 \%{ }^{9}$.

This study revealed that birth weight was $<2.5 \mathrm{Kgs}$ in $7 \%, 2.5-3.5 \mathrm{~kg}$ in $68 \%,>3.5 \mathrm{~kg}$ in $25 \%$ GDM mother. Makwana $\mathrm{M}$ also reported similar finding, 3 (7.9\%) baby's birth weight was $<2.5 \mathrm{Kgs}, 30(79 \%)$ weighed between 2.5-4 kgs and 5 (13.2\%) babies had birth weight $>4 \mathrm{kgs}^{19}$. Fetal Macrosomia (30-40\%) probably result from (a) maternal hyperglycaemia leads to hypertrophy and hyperplasia of fetal islets of Langerhans results increased secretion of fetal insulin which in turn causes increase stimulation of carbohydrate utilization and accumulation of fat. Insulin like growth factor (IGF- I \& II) are also involved in fetal growth and adiposity. With good diabetic control incidence of macrosomia is markedly reduced (b) Elevation of maternal free fatty acid (FFA) in diabetics leads to its increased transfer to the fetus causes fetal adiposity ${ }^{19}$.

\section{Conclusion}

Gestational diabetes complicating pregnancy has adverse maternal and fetal outcome. Early identification and better treatment of mothers and fetuses may have far reaching implications for maternal and child health. Since the only expenditure involved is a simple screening blood test, it is recommended that all patients be universally screened for GDM. In conclusion, a short term intensive care gives a long term pay off in the primary prevention of obesity, impaired glucose tolerance and diabetes in the off spring, as preventive medicine starts before birth. The maternal health and fetal outcome depends upon the care by the committed team of diabetologists, obstetricians and neonatologists.

\section{References}

1. Sayeed MA, Mahtab H, Khanam PA et al. Diabetes and hypertension in pregnancy in a rural community of Bangladesh: a population-based study. Diabet Med. 2005; 22:1267-71.

2. Jesmin $\mathrm{S}$, Akter $\mathrm{S}$, Akashi $\mathrm{H}$ et al. Screening for gestational diabetes mellitus and its prevalence in Bangladesh. Diabetes Res Clin Pract. 2014; 103:57-62. 
3. Metzger BE, Coustan DM. Organizing Committee: Summary and recommendations of the Fourth International WorkshopConference on Gestational Diabetes Mellitus. Diabetes Care. 1998; 21:161-7.

4. American diabetes association. Standards of medical care in diabetes-2010. Diabetes Care. 2010; 33; S11-S61.

5. International Diabetes Federation. Diabetes Atlas. 7th ed, 2015.

6. Nolan CJ. Controversies in gestational diabetes. Best Pract Res Clin Obstet Gynaecol. 2011; 25:37-49.

7. Abourawi Fl. Diabetes mellitus and pregnancy. Libyan J Med. 2006; 1:28-41.

8. Jesmin S, Jahan S, Khan Ml et al. The incidence, Predisposing Factors, Complication and Outcomes of Preeclamsia in Diabetes Pregnancy. Birdem Med J. 2011; 1:10-4.

9. Sajani TT, Rahman MT, Karim MR. Maternal and fetal outcome of mothers with gestational diabetes attending Birdem Hospital. Mymensingh Med J. 2014; 23(2):290-8.

10. Faroog MU, Ayaz A, Ali Bahoo L et al. Maternal and neonatal outcomes in gestational diabetes mellitus. Int J Endocrinol Metab. 2007; 3:109-15.

11. Kumari SS, Rani BS, Usha $P$ et al. Maternal and foetal outcome in gestational diabetes mellitus. J Evid Based Med Health. 2016; 3(75):4087-90.

12. Dahiya K, Sahu J, Dahiya A. Maternal and Fetal Outcome in
Gestational Diabetes Mellitus-A Study at Tertiary Health Centre in Northern India. Open Access Library Journal. 2014; 1:e500.

13. Jensen DM, Sorensen B, Feilberg JN et al. Maternal and perinatal outcomes in 143 Danish women with gestational diabetes mellitus and 143 controls with a similar risk profile. Diabetic Medicine. 2000; 17(4):281-286.

14. Johns K, Olynik C, Mase R et al. Gestational diabetes mellitus outcome in 394 patients. Journal of Obstetrics and Gynaecology Canada. 2006; 28(2):122-127.

15. Joy R, Sivakumar V. A prospective study on the effect of gestational diabetes mellitus on maternal and fetal outcome. IJPTP. 2012; 3(3):345-351.

16. Yajnik CS, Kale SD, Kulkarni SR et al. High risk of diabetes and metabolic syndrome in Indian women with gestational diabetes mellitus. Diabetes Medicine. 2004; 21:1257-9.

17. Biswas RT. Risk factors and pregnancy outcomes among gestational diabetic mothers: A hospital based study in Bangladesh (unpublished).

18. Shefali AK. Pregnancy outcomes in pre-gestational and gestational diabetic women in comparison to nondiabetic women a prospective study in Asian indian mothers. J Assoc Physicians India. 2006; 54:613-8.

19. Makwana M, Bhimwal RK, Ram C et al. Gestational diabetes mellitus with its maternal and foetal outcome-a clinical study. Int J Adv Med. 2017; 4:919-25. 